\section{Commentary: Arterial switch operation: It's the little things that count}

\author{
Harold M. Burkhart, MD, ${ }^{\mathrm{a}}$ Yuki Nakamura, MD, ${ }^{\mathrm{a}}$ and \\ Arshid Mir, MD ${ }^{\mathrm{b}}$
}

More than 4 decades ago, Jatene and colleagues ${ }^{1}$ introduced the first 2 cases of anatomic correction of transposition of the great vessels in The Journal of Thoracic and Cardiovascular Surgery. Quickly becoming the standard of care for surgical treatment of transposition, the arterial switch operation (ASO) continues to present challenges when it comes to complex coronary artery anatomy. Difficulties with coronary artery transfer secondary to an intramural course, a single ostium, or the inability to mobilize it adequately are just a few of the scenarios that can lead to coronary artery obstruction and ischemia. Ebels and colleagues ${ }^{2}$ reported the first neonatal coronary artery bypass to successfully manage this dreaded complication. A neonate with transposition of the great arteries (TGA) underwent an ASO with unsuccessful intramural left coronary artery translocation necessitating a rescue left internal mammary artery to left anterior descending coronary artery bypass.

In this issue of the JTCVS Techniques, Iwata and colleagues $^{3}$ describe 4 infants with an average weight of $4 \mathrm{~kg}$ who underwent totally microscopic coronary artery bypass grafting (CABG). Three of the patients had undergone ASO and needed a CABG within the same

From the a Division of Cardiovascular and Thoracic Surgery and ${ }^{\mathrm{b}}$ Section of Pediatric Cardiology, University of Oklahoma Health Sciences Center, Oklahoma City, Okla.

Disclosures: The authors reported no conflicts of interest.

The Journal policy requires editors and reviewers to disclose conflicts of interest and to decline handling or reviewing manuscripts for which they may have a conflict of interest. The editors and reviewers of this article have no conflicts of interest.

Received for publication Sept 20, 2021; revisions received Sept 20, 2021; accepted for publication Sept 24, 2021; available ahead of print Sept 28, 2021.

Address for reprints: Harold M. Burkhart, MD, Division of Cardiovascular and Thoracic Surgery, University of Oklahoma Health Sciences Center, P.O. Box 26901, WP-2230, Oklahoma City, OK 73105 (E-mail: Harold-burkhart@ouhsc. edu).

JTCVS Techniques 2021;10:446-7

2666-2507

Copyright (C) 2021 The Author(s). Published by Elsevier Inc. on behalf of The American Association for Thoracic Surgery. This is an open access article under the CC BY-NC-ND license (http://creativecommons.org/licenses/by-nc-nd/4.0/).

https://doi.org/10.1016/j.xjtc.2021.09.042

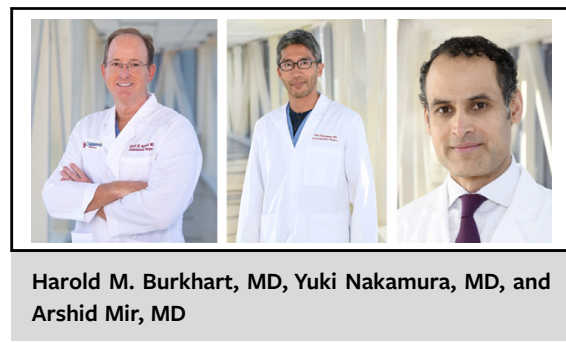

CENTRAL MESSAGE

Coronary transfer is critical in the arterial switch operation, as well as having a backup plan.

hospitalization or at a 3-month interval $(n=2)$. These 3 patients were alive after a follow-up of 8 years, 3 years, and 8 months. The fourth patient had a high-grade stenosis of the left main coronary artery without structural congenital cardiac disease. Despite excellent angiographic results, this patient passed away 2 months after discharge. This report represents a unique approach to a difficult situation encountered after the ASO. The technique of using a microscope along with interrupted sutures to perform a bypass graft in infants allows for successful outcomes in coronary arteries as small as $0.6 \mathrm{~mm}$. The authors should be congratulated on such impressive results. Unfortunately, details of the original coronary anatomy in the patients with TGA and precise information on the length and extension of the stenosis of the coronary arteries were lacking and may have been helpful when reflecting on how the need for CABG may have been avoided.

It should be pointed out that Kitamura and colleagues ${ }^{4}$ have a long history with the successful use of the microscope when performing pediatric CABG. Their largest pediatric experience is with 114 patients with Kawasaki disease needing CABG. The patients range from 1 to 19 years of age, with an average of 1.7 distal anastomoses per patient performed. There was no operative mortality, and 25-year survival was reported at $95 \%$. Remarkably, the 20-year patency rate for the internal thoracic artery graft was $87 \%$.

Other groups have reported success with CABG or arterioplasty in children. Thammineni and colleagues ${ }^{5}$ presented a 30-year experience with CABG/arterioplasty in the 47-center Pediatric Cardiac Care Consortium. In total, 137 patients ranging in age of 3 days to 17 years underwent CABG $(52 \%)$ or arterioplasty $(48 \%)$ for a variety of pathology, including TGA $(\mathrm{n}=30)$. Note that the TGA group was the largest group and accounted for 
$0.8 \%$ of the patients undergoing ASO in the consortium during that same time period. Operative mortality was $14.6 \%$, with 15 -year transplant-free survival being $90.7 \%$. Importantly, there was no difference in operative or long-term survival reported when patients undergoing CABG were compared with those undergoing arterioplasty. Vida and colleagues ${ }^{6}$ reported the European experience from 13 centers performing coronary artery revascularization in 80 pediatric patients (CABG: 65 patients). Mortality was similar at $15 \%$, with risk factors including emergent or rescue surgeries.

Alternate approaches to pediatric coronary ischemia have been described. Bergoënd and colleagues ${ }^{7}$ have reported excellent success with coronary artery proximal patch arterioplasty in 25 patients, 19 of whom were post-ASO. Two of these patients required CABG to address left anterior descending coronary artery stenosis from the patch arterioplasty. The authors also included 8 patients who underwent $\mathrm{CABG}$, with either symptoms or graft failure noted in more than one half at 3-year follow-up. The authors concluded that patch arterioplasty was an effective approach to enlarge the proximal coronary.

In conclusion, the current report serves 2 purposes. First, it reminds us of the critical nature of the coronary artery transfer in the ASO. Second, if the feared complication of coronary artery ischemia develops, it offers us a useful surgical approach that can be expanded to other pediatric coronary pathology.

\section{References}

1. Jatene AD, Fontes VF, Paulista PP, Souza LC, Neger F, Galantier M, et al. Anatomic correction of transposition of the great vessels. J Thorac Cardiovasc Surg. 1976;72:364-70.

2. Ebels T, Meuzelaar K, Gallandat Huet RC, Bink-Boelkens MT, CrommeDijkhuis A, Bams JL, et al. Neonatal arterial switch operation complicated by intramural left coronary artery and treated by left internal mammary artery bypass graft. J Thorac Cardiovasc Surg. 1989;97:473-5.

3. Iwata Y, Takeuchi T, Konuma T, Obase K, Eishi K. Infant coronary artery bypass grafting completely under surgical microscope. J Thorac Cardiovasc Surg Tech. 2021;10:441-3.

4. Kitamura S, Tsuda E, Kobayashi J, Nakajima H, Yoshikawa Y, Yagihara T, et al Twenty-five-year outcome of pediatric coronary artery bypass surgery for Kawasaki disease. Circulation. 2009;120:60-8.

5. Thammineni K, Vinocur JM, Harvey B, Menk JS, Kelleman MS, Korakiti AM et al. Outcomes after surgical coronary artery revascularisation in children with congenital heart disease. Heart. 2018;104:1417-23.

6. Vida VL, Torregrossa G, De Franceschi M, Padalino MA, Belli E, Berggren H, et al. Pediatric coronary artery revascularization: a European multicenter study. Ann Thorac Surg. 2013;96:898-903.

7. Bergoënd E, Raisky O, Degandt A, Tamisier D, Sidi D, Vouhé P. Myocardial revascularization in infants and children by means of coronary artery proximal patch arterioplasty or bypass grafting: a single-institution experience. J Thorac Cardiovasc Surg. 2008;136:298-305. 